\title{
An Investigation into Effective Ways to Involve Ethnic Minority Parents to Enhance the Chinese Learning of Their Children
}

\author{
Shek-Kam Tse*, Pik-Fong Tsui, Heiken To, Kam-Fong Wu, Victor Laing, Lu-Sai Lam \\ Faculty of Education, The University of Hong Kong, Hong Kong, China \\ Email: ^sktsebrian@gmail.com
}

How to cite this paper: Tse, S.-K., Tsui, P.-F., To, H., Wu, K.-F., Laing, V., \& Lam, L.-S. (2021). An Investigation into Effective Ways to Involve Ethnic Minority Parents to Enhance the Chinese Learning of Their Children. Open Journal of Social Sciences, 9, 137-150.

https://doi.org/10.4236/jss.2021.92009

Received: December 14, 2020

Accepted: February 7, 2021

Published: February 10, 2021

Copyright $\odot 2021$ by author(s) and Scientific Research Publishing Inc. This work is licensed under the Creative Commons Attribution International License (CC BY 4.0).

http://creativecommons.org/licenses/by/4.0/

\begin{abstract}
Parent involvement has been found to be vital to children's school success, as such, it is important to find ways to engage parents in students' learning activities, especially for those who came from culturally diverse background. This paper presents the concepts of parent involvement and uses a case as an exemplar to capture the facilitating factors for involving an ethnic minority (EM) parent for enhancing the Chinese learning of her child in the Hong Kong context. Qualitative results showed that successful factors for engaging EM parents include: having high learning motivation, good program elements (such as employing the pleasurable learning elements, being culturally sensitive), the establishment of a first language-like environment, and being empowered. Future directions for education and social service sectors for engaging EM parents are also discussed.
\end{abstract}

\section{Keywords}

Parent Involvement, Ethnic Minority Students, Chinese Learning, Chinese as a Second Language

\section{Introduction}

Parent involvement can be referred to parents' actively playing their roles both in school and at home for the benefit of the child's general development and education success (Borgonovi \& Montt, 2012). Parents are important to children's development, not only physically but also academically. Parental involvement has been found to be positively associated with children's school performance (Sheldon \& Epstein, 2005; Jeynes, 2007), language learning (Brannon \& Dauksas, 2012), and school participation (Simon, 2001); and negatively corre- 
lated with children behavior problems (Domina, 2005) and school dropout rates (Epstein \& Sheldon, 2002). As for preschoolers, family engagement plays an important role in early childhood education and it makes positive impacts on the children's development.

Family engagement is especially important to children and parents from diverse background because they may experience hardship due to the cultural and language differences (Massing, Kirova, \& Hennig, 2013). Among the ethnic minority group in Hong Kong, 9\% of them were aged under 15 (i.e., school age) (Census and Statistics Department, 2017), it is thus important to find ways to engage these parents to assist the learning of their children, so that they may integrate into the local society. In the following, the concept of parent involvement will be discussed followed by stating the services available for ethnic minority parents in Hong Kong. Next, the facilitators and barriers for parent involvement will be examined. Then, a case will be presented as an example for investigating the facilitating factors for involving ethnic minority parents in Hong Kong. At last, implications generated from the findings will be discussed.

\subsection{Parent Involvement}

Different parties view parental involvement in different senses. Parents may think providing a safe environment for the healthy growth of their children and making their children attending schools has fulfilled their parental roles, while teachers may think parental involvement is just parents' presence at school (Anderson \& Minkle, 2007). Various models have been proposed on parental involvement that support children's learning, in the present paper, two frameworks will be briefed: the funds of knowledge approach forwarded by Luis Moll, and the family-school partnerships framework suggested by Joyce Epstein (Grant \& Ray, 2019).

Funds of knowledge refer to the "historically accumulated and culturally developed bodies of knowledge and skills essential for households or individual functioning and well-being" (Moll, Amanti, Neff, \& Gonalez, 1992: p. 133). Unlike general perceptions that problems are always associated with ethnic minority families or families with low social-economic status, the funds-of-knowledge approach emphasizes on the cultural and cognitive resources that a family has for enhancing children's learning. Riojas-Cortez and Flores (2009) examined 65 Mexican immigrant and Mexican American families and found that these families had taught their children the social skills (e.g., active listening, verbal responses) or values (e.g., friendship, sharing, respect,) that were promoted in the Texas Prekindergarten Guidelines and these values and skills made the children more ready for kindergarten schooling. This approach not only invites educators to be more positive toward the uniqueness of the family values and cultures, but also redefines family-school relationship when educators have a better understanding of the daily routines of these ethnic minority families. Teachers can design class activities that are related to children's ethnic cultures and invite their 
parents to be expert presenters of that particular culture (Weiss et al., 2005). That is, parents' knowledge can be utilized to enhance their children's learning.

In the family-school partnerships framework, Epstein (2011) has developed six types of parental involvement, as a continuum of commitment, from basic obligations of families to collaborations and exchanges with the community. The six types of involvement are: 1) Parenting-Families support the basic needs for children (i.e., shelter, food, health and safety, and child rearing) and schools help families by organizing support programs to educate parents about parenting skills. 2) Communicating-Schools and parents use different channels to communicate effectively about school programs and students' progress; and the language used should be understood by all parents. 3) Volunteering-Parents can use their talents and skills to serve as volunteers to support schools and students; or just present themselves as audiences in school activities (e.g., assemblies, performances, sports day ... etc.). 4) Learning at home-Parents assist in children's academic affairs at home (monitoring, discussing, helping, following-up) so that children can do better in school. 5) Decision making-Parents involve in the decision making of schools by joining Parents-Teacher Associations or school-site management teams. 6) Collaborating-Schools, students, and families are linked with the community while mutual understanding can be achieved; while community organizations can help to enrich school programs, students and parents can work as volunteers to serve the community.

Regarding early childhood education in the Hong Kong context, Cheung and Kam (2019) perceived that parenting and communicating were the two most important among the six types of parental involvement as proposed by Epstein (2011). Nevertheless, these two types were regarded of less feasibility in terms of implementation, and the teachers also reported of having low confidence in helping parents regarding effective parenting. As suggested by Baum and McMurray-Schwarz (2004), some parents feel offended when being informed by teachers about their children's problems at school and ways for improving their parenting skills. While the study highlighted pre-service early childhood teachers' reassurance about the importance of parental engagement in children's learning at home, this element needs to be implemented as part of the contribution to children's learning success.

\subsection{Hong Kong Government's and NGOs' Efforts to Promoting Parent Involvement}

Promoting parents' participation into school affairs has always been advocated by the Hong Kong government and resources have been allocated for such purpose since 1993. Currently, all government and aided secondary and primary schools have set up Parent-teacher Associations for better communication between family and school. However, only one-thirds of the kindergartens have Parent-teacher Associations, which means this official channel for home-school communication is not available in every kindergarten (Task Force on Home 
School Co-operation and Parent Education, 2019).

EM people constituted $3.6 \%$ of the whole Hong Kong population and their ethnicities included Nepalese, Indian, Pakistani, Filipino, Vietnamese, Bangladeshi ...; among them, one-fifth were at school age (Census and Statistics Department, 2017). Despite the manpower and financial resources invested by the Hong Kong Education Bureau (EDB) in advancing home-school cooperation, the needs of EM children are not fully addressed. Currently, efforts to assist these students are mainly informative and focused on older students. For example, there is a website operated by EDB listing the educational services available, an e-version of parent information package for EM parents, a Student Support Program to help EM students learning Chinese, moreover, funding is also allocated to schools admitting EM students for designing school-based curriculum to cater the learning needs of these students (EDB, 2019a; 2019b). In spite of the available services, assistants to EM parents, whose themselves have very limited Chinese language proficiency or limited knowledge about the local society, are far from enough. The needs of parents of EM students should be addressed and parent education for this particular group should be encouraged (Task Force on Home School Co-Operation and Parent Education, 2019).

Hong Kong non-government organizations (NGOs) have long history of providing family support services and parenting education for families in need. There are also social services to help ethnic minority groups in Hong Kong, such as language programs, cultural exchange events, interest classes, home services, outreach services, interpretation services, etc. (for example, International Social Service Hong Kong Branch, 2019; Social Welfare Department, 2020; Hong Kong Christian Services, n.d.). Nonetheless, most services are mainly for local families and their clientele are not pinpointing to EM kindergarten children and their families.

\subsection{Facilitators and Barriers to Parent Involvement}

Factors have been found to associate with the significance of parent involvement in previous studies. In a self-reported study targeting parents of elementary students from public schools, Smith et al. (1997) reported that positive school climate such as learning atmosphere and range of activities directly decreased barriers such as work schedule and transportation and fostered attitude toward involvement in reading to children at home, which in turn contributed more to parent involvement at home such as reading to their child and checking homework. Oswald et al. (2018) found that involvement made by parents of students from kindergarten through 12th grade in participation at the child's school and school meetings, in learning activities at home and in the community, and in homework checking were predicted by certain variables. Predictors included child characteristics such as race or ethnicity, family demographics such as parent education level, school characteristics such as size, child's school experience such as school enjoyment, and parent satisfaction with how school interacts with 
parents. When concerning families from diverse backgrounds, Naughton (2004) concluded that programs that can successfully engage families are those "focus on building trusting collaborative relationship" and "recognize, respect, and address families' needs, as well as class and cultural differences" (p. 5).

Nevertheless, there are lots of factors hindering minority parents to engage in their children's academic pursuit as stated in western research, such as lack of language proficiency, low educational level, low socioeconomic status, or lacking social networks, lacking time and material resources, etc. (Kim, 2009; Massing, Kirova, \& Hennig, 2013; Grant \& Ray, 2019). Similar barriers also prohibit the involvement of EM parents into school activities in Hong Kong. In addition to language barriers, limited knowledge about the local society and the Chinese culture always create great difficulties on EM parents to help their children to learn Chinese or integrate into the society (Yuen, 2018).

\section{The Current Study}

To fill the service gap to help EM children and their families learning Chinese (referring to Cantonese and traditional Chinese characters), The Hong Kong Jockey Club Charities Trust initiated the "C-for-Chinese@JC" project in 2016. The project adopts a home-school-community model which is originating from the ecological approach. From the ecological perspective, the microsystem (i.e., the immediate environment of children such as their family, peers, teachers, and neighbors) has most impacts on one's development.

The current study employs a qualitative case study approach through field observation to investigate the facilitators for engaging EM parents to assist their children to learn Chinese in a home domain program, the parent-led home program (PLHP). The objectives of PLHP are to expand parent's awareness, self-efficacy, and strategies in helping children's Chinese learning at home and in the community. The program contains nine sessions of one-on-one home visit, each session lasting for 45 to 60 minutes. Sessions are well structured, starting from understanding the family background and the home environment, to introducing the project details, and to create an environment favorable to the learning of Chinese at home.

\section{Methodology}

\subsection{Participant}

All participants in the "C-for-Chinese@JC" program were encouraged to join different kinds of school, home, and community activities. The child in the present case study, Yoo (pseudonym), and his mother were invited to join the PLHP because the family was identified as having high motivation toward learning Chinese.

Yoo was a Pakistan born in Hong Kong and the fifth-born child in his family. His father was born in Hong Kong and married her mother in Pakistan. His two elder sisters and an elder brother were born in Pakistan and went to Hong Kong 
with his mother eight years ago. In this family, Yoo's mother was the primary caregiver while the father was the only bread winner. At the time of the study, Yoo's elder siblings aged 12 and 13 while Yoo was three years old and studying in K1. His another sister, aged 7, was also born in Hong Kong and was studying in primary 2.

All family members spoke Punjabi (Pothwari) as their first language and they also could speak English. In addition to Pothwari and English, Yoo's mother could speak a little bit of Cantonese.

\subsection{Data Collection and Procedures}

Yoo's Chinese language proficiency (listening, speaking, and reading abilities) was tested at the beginning and the end of $\mathrm{K} 1$ using the Chinese Language Learning Progression Framework for Non-Chinese Speaking Children in Kindergartens in Hong Kong (Lam, Hui, \& Cheung, 2018), details of the instrument please refer to Tse et al. (2020). The results of the tests were divided into 5 levels (levels $0,1,2,3$, and $3^{*}$ ), whereas the higher the level, the better the Chinese language proficiency. Yoo attained level 0 in speaking and reading abilities, and level 1 in the listening ability in the pre-test.

Before starting the PLHP, Yoo's mother participated in group workshops to learn basic Cantonese and prompting skills through role play activities. For example, she learned to use the question "What is this?" to practice speaking and writing in Chinese with her child. With this approach, parents learnt from their children while they were practizing Chinese at home. In addition, a social worker paid a home visit to Yoo's family to study his family background, and to discuss with the mother about the learning goals and teaching methods in accordance with the family's needs and their level of Chinese abilities. It revealed that the family faced difficulties in interacting with local people, especially in special contexts such as in hospitals, the immigration department or at schools. The mother found it hard to express their problems in Chinese to others. It made them even more introvert. The mother's wish for Yoo was that he could communicate in Chinese and his Chinese level could attain the entry requirement for universities.

The home sessions ran from February to May, 2019. A kindergarten teacher from the NGO conducted the PLHP program at Yoo's home and a social worker did the field observations throughout the nine sessions. Naturalistic observation was chosen as the data collection method because it could provide a comprehensive picture on what actually happened during the training sessions, and thus allowed an in-depth investigation of factors which were conducive to parent involvement; moreover, as Yoo was so young and his mother was an ethnic minority woman who might be less articulate, the observations conducted in an environment that they were familiar with could provide a way of capturing their performance in their most genuine manner (Simons, 2009).

The observation notes of the nine sessions were analyzed by a trained research 
assistant. In addition, the social worker conducted individual follow up meetings with parents once every two weeks to review the progress. The parent consent was obtained before the data collection. Table 1 presents the content of each family session.

\section{Findings}

The Chinese ability of Yoo after the completion of PLHP was regarded to have good improvement, especially in the follow-up test in K3. In K3, he progressed from Level 1 to Level $3^{*}$ in the Listening test, and from Level 0 to Level 3 in both Speaking and Reading tests.

By the end of the PLHP, Yoo was able to point out facial parts in Cantonese when being shown a picture and he could recognize the Chinese characters "eye", "mouth", "hand", and "foot". He also had the chances to practice short sentences in Cantonese in real situations, like having meal in a restaurant or shopping in a supermarket. Regarding Yoo's progress in his Chinese language proficiency, this case can be regarded as an exemplar. In investigating the field observation notes, the following facilitators which help facilitate parents' engagement can be identified.

Table 1. Program content of each PLHP session.

\begin{tabular}{|c|c|}
\hline Session & Content \\
\hline 1 & $\begin{array}{l}\text { - Introduce the use of Chinese in storytelling and games } \\
\text { - Encourage parents to cultivate the habit of reading with their children }\end{array}$ \\
\hline 2 & $\begin{array}{l}\text { - Revise the Chinese names of "eye", "ear", "mouth", and "nose" } \\
\text { - Introduce the interrogative, "What's it?" and the statement, "It's..." in Chinese. }\end{array}$ \\
\hline 3 & $\begin{array}{l}\text { - Revise the Chinese names of "eye", "ear", "mouth", and "nose" } \\
\text { - Strengthen parent involvement }\end{array}$ \\
\hline 4 & $\begin{array}{l}\text { - Revise the Chinese names of "eye", "ear", "mouth", and "nose" } \\
\text { - Strengthen parent involvement }\end{array}$ \\
\hline 5 & $\begin{array}{l}\text { - Enhance the speaking abilities of parents } \\
\text { - Introduce family reading activities }\end{array}$ \\
\hline 6 & $\begin{array}{l}\text { - Get to know other members in the PLHP program } \\
\text { - Conclude and apply the program content } \\
\text { - Add cultural responsive elements into activities } \\
\text { - Get to know the community }\end{array}$ \\
\hline 7 & $\begin{array}{l}\text { - Construct a Chinese home learning environment } \\
\text { - Learn Chinese in daily lives }\end{array}$ \\
\hline 8 & $\begin{array}{l}\text { - Introduce the radical of the Chinese word "mouth" } \\
\text { - Draw attention to the use of Chinese in daily lives }\end{array}$ \\
\hline 9 & - Introduce the use of information technology \\
\hline
\end{tabular}




\subsection{Having High Motivation during the Learning Process}

The observation notes revealed that Yoo's mother had high motivation during the learning process. She attended all the nine PLHP sessions and her 7-year-old daughter joined four of them. The mother was eager in learning new strategies for helping Yoo to learn Chinese at home. For example, the kindergarten teacher intensively taught the mother about questioning sentences recommended in the book and the latter marked them with her mother-tongue language. During the sessions, the mother had onsite practices of the question and answer patterns, such as "What is it? It is ..." and "What is the use of this? This is used for ..." with Yoo. The mother would point to different facial parts and asked "What is this?", and Yoo answered "hand", "eye", "nose", "ear", "mouth" and "leg" respectively using the sentence structure "This is ...". As such, Chinese naming of facial parts were revisited, and the speaking proficiency of Yoo was thus enhanced.

Yoo's mother showed a decisive mind during the PLHP sessions. Apart from lessons, there were homework after each PLHP, such as storybook reading exercise, word-picture matching game, or colouring exercises. The mother was very cooperative and did the homework as assigned. Flashcards showing pictures with Cantonese pronunciation were left for his mother after the second session, and the mother pinned them all on the wall.

\subsection{Good Program Elements}

The design of the PLHP program had considered culturally relevant elements to cater for the needs of EM learners and their parents who were not familiar with the local education system as well as the Chinese language. Its content ranged from teaching parents of using questioning sentences in Cantonese to getting to know the community. This made the mother and Yoo felt comfortable when engaging themselves in the program.

The principle of pleasurable learning was upheld in the PLHP program. This parent involvement program allowed participants to learn Chinese through games and activities, such as word-picture matching game, electric finish game, video watching, and outings at a nearby restaurant and a public library. The program was interactive and full of fun. The parent-child storybook reading time was introduced. By doing so, the mother could try reading the storybook and practicing those sentence structures with the child at home.

The PLHP also applied a systematic approach of Chinese learning, from listening to reading. Taking the teaching of the word "mouth" as an example, the teacher started with teaching the pronunciation of the word, then moved to picture-word matching where Yoo could identify the Chinese character and the meaning of the word, then Yoo could identify the Chinese word "mouth" without picture assistance. After recognizing the word, Yoo was arranged to practice the sentence structure using the word "mouth", such as "What's the mouth used for?", and Yoo answered "for eating" where Yoo tried to speak a short phrase in 
Cantonese. As the program was tailor-made to fit Yoo's Chinese ability, the learning pace was adjusted according to the child's progress to minimize confusion and allow the child to have a thorough understanding of Chinese. This systematic approach also provided a sense of achievement to the mother when she practiced Chinese with Yoo because she could witness the improvement in her son.

\subsection{Establishment of a First-Language Like Environment at Home}

Before the program, the family only had schoolbooks written in Chinese. With the help of the kindergarten teacher, the mother decorated their home with a small Chinese learning corner. A poster printed with vegetables and fruits and the Chinese names of them was hanged on the wall. The home was also equipped with flash cards, and vocabulary posters with pictures and Chinese words. The mother also learnt to use mobile applications (e.g. google translate) to search the meaning when she came across Chinese words she did not know. Apart from this, some cartoons in Cantonese were also introduced, the links in Youtube were set in the mother's cell phone. With the help of the technology, the mother could access more useful resources to help Yoo to learn Chinese.

In addition to the physical environment, the mother also encouraged Yoo's siblings to use Cantonese more often in their daily conversations. As such, Yoo had more chances to use Chinese to communicate with his mother as well as his siblings, thus creating a first-language like environment for Yoo to practice Chinese.

\subsection{Being Empowered}

During the PLHP sessions, Yoo's mother learned about effective learning strategies as well as the basic information of the Hong Kong society. She also learned the tone, technique, and strategies of parent-child storytelling under the demonstration of the kindergarten teacher. Moreover, Yoo's mother observed how to teach Chinese to her son and learned how to decorate a home environment facilitating the learning of Chinese. She also got to know the methods of using the parent handbook, IT apps and the Chinese learning games. With skills and strategies equipped to enhance Yoo's learning, the parent's self-efficacy and confidence were reinforced.

\section{Discussion}

The present study investigated the facilitating factors for engaging EM parents in their children's Chinese learning; the results from the case study provide insights for how to effectively involve parents in their children's academic pursuits.

Parent involvement plays an important role in early childhood education and it makes positive impacts on children's development. In a study to train low-income Hispanic parents about dialogic reading, parents or caregivers in the experimental group were found significantly more capable to promote reading and use li- 
teracy strategies to help their children's language learning; and their children (aged 3 to 4 ) were also found to acquire significantly more words than those children whose parents were in the comparison group (Brannon \& Dauksas, 2012). This signifies that parents could help their children's language learning by acquiring appropriate skills and the same can be observed in the current study. That is, Yoo's Chinese language proficiency was improved with his mother engaged with him in a home program in which the mother learned parent-child reading skills and strategies.

Consistent with Naughton's (2004) summarization, the PLHP respects the uniqueness of the participating families and the program is tailor-made to suit the families' needs and their language ability and these are the successful factors to engage EM parents. As PLHP is a not simply a Chinese language enhancement program for EM students, it also recognizes the cultural differences between EM and local students. All these make EM parents more willing to join the program. To address the barriers prohibiting EM parents from involving in educational-related programs, schools and social service agencies should be more sensitive to the cultural differences and the difficulties these EM parents are encountering if they want to involve parents in children's learning.

As most studies confirmed, learners' learning motivation is crucial to the success of second language learning (e.g., Cheng \& Dornyei, 2007; Guilloteaux \& Dornyei, 2018). In the present study, we found that the parent who was highly motivated also played an important role in children's learning. The mother's high participation rate, her cooperation with the social service agency in doing the assigned homework, and her willingness to change the home environment facilitated the Chinese learning of her son. This may be due to the high aspiration of the parent toward her son's multilingual education and the result resonates the study of van Mensel and Deconinck (2019). Instead of examining learners' motivation, van Mensel and Deconinck investigated the projected desire of parents on children's language learning through interviews. Results revealed that immigrant parents had the thought that the mastery of first language in the society and other languages was associated with better future achievement of their children whereas local parents "do not at any point frame their wish to have multilingual children in terms of the economic or professional benefits that this may reap" (p. 544). In the present study, the expectation of the mother was that her child's Chinese language proficiency to meet the university entry requirements and this is the force that motivates the mother to engage actively in the program. As such, future services should put emphasis on motivating EM parents.

The empowerment of parents is another point that is worth noting. In the school context, parent empowerment can be referred to parents having the sense of capacities, mastery, and competence to facilitate the effective learning of their children (Kim \& Bryan, 2017). Naughton (2004) emphasized family engagement could improve the parent-child relationship and could also be seen as an oppor- 
tunity to empower parents, improve their self-confidence and to be an "effective advocate" of their children. In the present study, the mother came to realize the importance of learning Chinese. She learned skills that were useful to enhance the Chinese language abilities of her son. She was able to read Chinese storybooks or play language games with her son. With the help from the NGO's staff, the mother was capable to reconstruct a first language-like language environment for her son. She created a Chinese corner decorating with Chinese word cards, pictures, and posters that facilitated the Chinese learning at home as well as encouraging the whole family to use more Chinese. All these created a sense of control and a sense of success for the mother, especially when she noticed that her son's Chinese language ability was improved after the program. The mother became aware that her own strength could help her son thrive. This is especially important for EM learners who have limited opportunities to expose to Chinese language environment because of their strong in-group bonding among people of the same ethnicity (Tsung \& Gao, 2012). As the funds of knowledge (Moll et al., 1992) advocates, the cultural uniqueness of the ethnic minority groups can be viewed as the valuable assets of the family. By seeing families from diverse backgrounds from a different perspective, these families are no longer regarded as problematic. If schools or social service agencies could find ways to utilize the cultural assets of these EM families, such as inviting parents to be volunteers in school or social activities to share their cultural characteristics, these families would find themselves being more connected to schools and to the society. They would develop a sense of capability by contributing their strengths to the betterment of the school or the society. The local citizens would also find themselves being more familiar with other culture, thus social integration can be promoted.

Last but not the least, the principal of pleasurable learning, which is the guiding principle in the "C-for-Chinese@JC" project, is emphasized in this home domain program. The NGO has designed different games and activities to engage participants to learn Chinese in a pleasurable way, such as drawings, word-picture matching games, electric fishing game, outings, parent-child reading exercise, using of multi-media devices, etc. The interesting and joyful experiences provided to both the parent and the child successfully engaged them to actively participate in the program. The mother, who herself may not have experience of learning happily in her childhood, would find the whole program interesting for participating, though it is an educational program. The happy atmosphere would certainly sustain the parent to be a more active learner even after the termination of the PLHP program.

\section{Limitations and Conclusion}

There are some limitations to the present study. Firstly, there is only one case in the present study and this affects the generalization of the data. It would be better if more cases can be included. Secondly, the case study only conducted in the 
form of field observations. It would be more informative and comprehensive if interviews could be conducted to elicit parents' firsthand experiences and comments about the program and maybe some obstacles or barriers impeding parents for engagement could be identified. Moreover, it would be interesting if cases with low motivation were involved so to verify if the facilitators found in the study could also work well in parents who may not be enthusiastic in helping their children in improving Chinese. Despite these limitations, the successful factors found in the present study could provide some guidelines for educators or social workers to engage EM parents for the betterment of children's development, especially when there is a dearth of local studies relating to EM parent involvement.

\section{Funding/Financial Support}

This work and the "C-for-Chinese@JC" project were supported by The Hong Kong Jockey Club Charities Trust.

\section{Conflicts of Interest}

The authors declare no conflicts of interest regarding the publication of this paper.

\section{References}

Anderson, K. J., \& Minke, K. M. (2007). Parent Involvement in Education: Toward an Understanding of Parents' Decision Making. The Journal of Educational Research, 100, 311-323. https://doi.org/10.3200/JOER.100.5.311-323

Baum, A. C., \& McMurray-Schwarz, P. (2004). Preservice Teachers' Beliefs about Family Involvement: Implications for Teacher Education. Early Childhood Education Journal, 32, 57-61. https://doi.org/10.1023/B:ECEJ.0000039645.97144.02

Borgonovi, F., \& Montt, G. (2012). Parental Involvement in Selected PISA Countries and Economies. OECD Education Working Papers, No. 73, Paris: Organization for Economic Co-Operation and Development.

Brannon, D., \& Dauksas, L. (2012). Increasing the Expressive Vocabulary of Young Children Learning English as a Second Language through Parent Involvement. Procedia, Social and Behavioral Sciences, 69, 1324-1331. https://doi.org/10.1016/j.sbspro.2012.12.069

Census and Statistics Department, Hong Kong Special Administrative Region (2017). 2016 Population By-Census - Thematic Report: Ethnic Minorities. Hong Kong: Census and Statistics Department. https://www.statistics.gov.hk/pub/B11201002016XXXXB0100.pdf

Cheng, H., \& Dornyei, Z. (2007). The Use of Motivational Strategies in Language Instruction: The Case of EFL Teaching in Taiwan. Innovation in Language Learning and Teaching, 1, 153-174. https://doi.org/10.2167/illt048.0

Cheung, S., \& Kam, C. (2019). Hong Kong Pre-Service Early Childhood Teachers' Attitudes towards Parental Involvement and the Role of Their Family Relationship Quality. Journal of Education for Teaching, 45, 417-433. https://doi.org/10.1080/02607476.2019.1639261

Domina, T. (2005). Leveling the Home Advantage: Assessing the Effectiveness of Parental 
Involvement in Elementary School. Sociology of Education, 78, 233-249. https://doi.org/10.1177\%2F003804070507800303

Education Bureau (2019a). Education Services for Non-Chinese Speaking (NCS) Students.

https://www.edb.gov.hk/en/student-parents/ncs-students/about-ncs-students/index.ht $\underline{\mathrm{ml}}$

Education Bureau (2019b). Non-Chinese Speaking Parent Information Package: Your Guide to Education in Hong Kong (E-Version).

https://www.edb.gov.hk/en/student-parents/ncs-students/support-to-student-and-pare nts/package/ncs-parent-information-package-chi eng.html

Epstein, J. L. (2011). School, Family, and Community Partnerships: Preparing Educators and Improving Schools (2nd ed.). Boulder, CO: Westview Press.

Epstein, J., \& Sheldon, S. (2002). Present and Accounted for: Improving Student Attendance through Family and Community Involvement. The Journal of Educational Research, 95, 308-318. https://doi.org/10.1080/00220670209596604

Grant, K. B., \& Ray, J. (2019). Home, School, and Community Collaboration: Culturally Responsive Family Engagement (4th ed.). Thousand Oaks, CA: SAGE Publications, Inc.

Guilloteaux, M. J., \& Dornyei, Z. (2008). Motivating Language Learners: A Classroom-oriented Investigation of the Effects of Motivational Strategies on Student Motivation. TESOL Quarterly, 42, 55-77. https://doi.org/10.1002/j.1545-7249.2008.tb00207.x

Hong Kong Christian Services. (n.d.). Centre for Harmony and Enhancement of Ethnic Minority Residents. https://hkcscheer.net/

International Social Service Hong Kong Branch (2019). Hope Centre for Ethnic Minorities. http://www.isshk.org/en/our services/detail/34

Jeynes, W. H. (2007). The Relation between Parental Involvement and Urban Secondary School Student Academic Achievement: A Meta-Analysis. Urban Education, 42, 82-110. https://doi.org/10.1177\%2F0042085906293818

Kim, J., \& Bryan, J. (2017). A First Step to a Conceptual Framework of Parent Empowerment: Exploring Relationships between Parent Empowerment and Academic Performance in a National Sample. Journal of Counseling and Development, 95, 168-179. https://doi.org/10.1002/jcad.12129

Kim, Y. (2009). Minority Parental Involvement and School Barriers: Moving the Focus Away from Deficiencies of Parents. Educational Research Review, 4, 80-102. https://doi.org/10.1016/j.edurev.2009.02.003

Lam, W. I., Hui, S. Y., \& Cheung, W. M. (2018). Chinese Language Learning Progression Framework for Non-Chinese Speaking Children in Kindergartens in Hong Kong. Hong Kong: Centre for Advancement of Chinese Language Education and Research.

Massing, C., Kirova, A., \& Hennig, K. (2013). The Role of First Language Facilitators in Redefining Parent Involvement: Newcomer Families' Funds of Knowledge in an Intercultural Preschool Program. Canadian Children, 38, 4-13.

https://doi.org/10.18357/jcs.v38i2.15445

Moll, L., Amanti, C., Neff, D., \& González, N. (1992). Funds of Knowledge for Teaching: A Qualitative Approach to Developing Strategic Connections between Homes and Classrooms. Theory into Practice, 31, 132-141.

https://doi.org/10.1080/00405849209543534

Naughton, S. (2004). English Language Learners, Immigrant Children and Preschool for 
All. The Importance of Family Engagement: An Issue Brief Series. https://files.eric.ed.gov/fulltext/ED486411.pdf

Oswald, D. P., Zaidi, H. B., Cheatham, D. S., \& Brody, K. G. D. (2018). Correlates of Parent Involvement in Students' Learning: Examination of a National Data Set. Journal of Child and Family Studies, 27, 316-323. https://doi.org/10.1007/s10826-017-0876-4

Riojas-Cortez, M., \& Flores, B. B. (2009). Supporting Preschoolers' Social Development in School through Funds of Knowledge. Journal of Early Childhood Research, 7, 185-199. https://doi.org/10.1177\%2F1476718X09102651

Sheldon, S. B., \& Epstein, J. L. (2005). Involvement Counts: Family and Community Partnerships and Mathematics Achievement. The Journal of Educational Research, 98, 196-206. https://doi.org/10.3200/JOER.98.4.196-207

Simon, B. S. (2001). Family Involvement in High School: Predictors and Effects. NASSP Bulletin, 85, 8-19. https://doi.org/10.1177\%2F019263650108562702

Simons, H. (2009). Case Study Research in Practice. London: SAGE Publications Ltd. https://dx.doi.org/10.4135/9781446268322

Smith, E. P., Connell, C. M., Wright, G., Sizer, M., Norman, J. M., Hurley, A., \& Walker, S. N. (1997). An Ecological Model of Home, School, and Community Partnerships: Implications for Research and Practice. Journal of Educational and Psychological Consultation, 8, 339-360. https://doi.org/10.1207/s1532768xjepc0804 2

Social Welfare Department (2020). Outreaching Teams for Ethnic Minorities. https://www.swd.gov.hk/en/index/site pubsvc/page family/sub listofserv/id otem/

Task Force on Home School Co-Operation and Parent Education (2019). Positive Parenting, Cross-Sector Collaboration and Innovation Foster Healthy Child Development.

https://www.e-c.edu.hk/doc/en/publications and related documents/education repor ts/Report TF\%20on\%20HSC en.pdf

Tse, S. K., To, H., Pang, E. Y. W., Tsui, P. F., Lam, L. S., Laing, V., \& Wu, K. F. (2020). Using the Home-school-community Model to Enhance the Chinese Language Proficiency of Non-Chinese Speaking Children. Creative Education, 11, 2069-2095. https://doi.org/10.4236/ce.2020.1110151

Tsung, L., \& Gao, F. (2012). What Accounts for the Underachievement of South Asians in Hong Kong? The Voices of Pakistani and Nepalese Parents. Educational Research, 54, 51-63. https://doi.org/10.1080/00131881.2012.658199

Van Mensel, L., \& Deconinck, J. (2019). Language Learning Motivation and Projected Desire: An Interview Study with Parents of Young Language Learners. International Journal of Bilingual Education and Bilingualism, 22, 535-550. https://doi.org/10.1080/13670050.2016.1272543

Weiss, H. B., Kreider, H., Lopez, M. E., \& Chatman, C. M. (2005). Preparing Educators to Involve Families: From Theory to Practice. Thousand Oaks, CA: Sage.

Yuen, C. Y. M. (2018). Social Equity and Home-School Collaboration in Multicultural Early Years' Education-A Hong Kong Perspective. In Y. Guo (Ed.), Home-School Relations: International Perspectives (pp. 137-153). Singapore: Springer. https://doi.org/10.1007/978-981-13-0324-1 8 